\title{
Mutation detection analysis of a region of I 6S-like ribosomal RNA gene of Entamoeba histolytica, Entamoeba dispar and Entamoeba moshkovskii
}

\author{
Subhash Chandra Parija*† and Krishna Khairnar ${ }^{\dagger}$
}

\author{
Address: Department of Microbiology, Jawaharlal Institute of Postgraduate, Medical Education and Research, Puducherry, 605006, India \\ Email: Subhash Chandra Parija* - subhashparija@yahoo.co.in; Krishna Khairnar - kskhairnar@yahoo.co.in \\ * Corresponding author †Equal contributors
}

Published: 26 September 2008

BMC Infectious Diseases 2008, 8:131 doi:10.1186/147|-2334-8-131
Received: 29 April 2008

Accepted: 26 September 2008

This article is available from: http://www.biomedcentral.com/I47I-2334/8//3।

(c) 2008 Parija and Khairnar; licensee BioMed Central Ltd.

This is an Open Access article distributed under the terms of the Creative Commons Attribution License (http://creativecommons.org/licenses/by/2.0), which permits unrestricted use, distribution, and reproduction in any medium, provided the original work is properly cited.

\begin{abstract}
Background: The level of intra-species genetic variation in Entamoeba histolytica, Entamoeba dispar and Entamoeba moshkovskii populations in a localized geographic area, like Puducherry, India, remains unknown.

Methods: In the present study the existence of genetic variation in the nested multiplex polymerase chain reaction (NM-PCR) amplified region of the 16S-like ribosomal RNA genes of $E$. histolytica, $E$. dispar and E. moshkovskii was investigated by riboprinting and single strand conformation polymorphism (SSCP) analysis.

Results: We found that 70 stool specimens were positive for $E$. histolytica, $|7|$ stool specimens were positive for E. dispar, and 37 stool specimens were positive for E. moshkovskii by NM-PCR. Ninety liver abscess pus specimens, $2 \mathrm{I}$ urine specimens, and 8 saliva specimens were positive for E. histolytica by NM-PCR. Riboprinting analysis detected a mutation in the PCR product of only one E. histolytica isolate from a stool specimen. However, SSCP analysis detected mutations in the PCR products of five $E$. histolytica isolates and three $E$. moshkovskii isolates from stool specimens, and one $E$. histolytica isolate from a saliva specimen. The mutations detected by riboprinting and SSCP analysis were confirmed by sequencing. All the nucleotide sequences showing mutations in this study have already been deposited into the NCBI GenBank database under accession numbers [GenBank: EF682200 to GenBank: EF682208].

Conclusion: The present study has revealed the subsistence of mutations in the ribosomal RNA genes of $E$. histolytica and E. moshkovskii, which points towards the existence of intra-species genetic variation in $E$. histolytica and $E$. moshkovskii isolates infecting humans.
\end{abstract}

\section{Background}

The protozoan parasite Entamoeba histolytica is estimated to infect 50 million people and cause 40,000 to 100,000 deaths annually, making it the second largest cause of mortality from infection with parasitic protozoa after malaria [1].
Although the first description of amoebiasis was more than a century ago [2], there is still uncertainty as to why symptoms of the disease appear only in $10 \%$ of those infected with E. histolytica while majority remains asymptomatic [3]. There have been several suggestions regarding the factors that may contribute to the outcome of amoebic 
infection in a susceptible host, which include a range of virulence levels among the E. histolytica strains and variability in host immunity against amoebic invasion. While the variability of human immunity against amoebic infection is not well understood, the existence of genetic variation in E. histolytica has been studied in depth recently [417]. These studies have identified genetic variation in protein-coding sequences of $E$. histolytica, such as those for the serine-rich E. histolytica protein [10-15] and chitinase $[8,11,12]$, as well as non-protein-coding regions such as the ribosomal RNA (rRNA) genes [4,5,7] and loci $1-2$ and $5-6[11,12,16,17]$. In addition, the existence of genetic variation in non-protein-coding loci 1-2 and 5-6 [18], as well as protein-coding chitinase gene of $E$. dispar has been reported recently [19].

These genetic variation studies appear to be promising in investigating the molecular epidemiology of amoebiasis. The existence of significant genetic variation among $E$. histolytica isolates collected from a wide geographical range, including Mexico, Bangladesh, India, Venezuela, South Africa, the Philippines, and Georgia, has already been demonstrated $[8,9,13,14]$. However, whether intra-species genetic variation also exists in E. histolytica, Entamoeba dispar and Entamoeba moshkovskii from a population in a restricted geographic area like Puducherry, India, still remains unknown.

The rRNAs, especially the 16S rRNA, have been widely used for studying genetic variation because of their conservative nature and universal distribution [20]. In the present study an attempt has been made to study genetic variation in regions of the 16S-like rRNA gene of $E$. histolytica, E. dispar and E. moshkovskii using riboprinting and single strand conformation polymorphism (SSCP) analysis followed by confirmation by nucleotide sequencing.

\section{Methods}

\section{Sample details}

The study was conducted at the Jawaharlal Institute of Postgraduate Medical Education and Research (JIPMER) hospital, Puducherry, India, during the period from July 2004 to July 2006. Informed consent was obtained from the patients. The study was approved by the Institute Human Ethics Committee (JIPMER, Puducherry, India).

\section{Stool}

Fresh unpreserved stool samples from 202 patients with complaints of gastrointestinal discomfort and positive for E. histolytica, E. dispar, or E. moshkovskii by microscopy or culture were collected in sterile capped containers and stored at $-20^{\circ} \mathrm{C}$ until used.

\section{Liver abscess pus}

The liver abscess pus aspiration was performed only for clinical purposes, as judged necessary by the clinicians for the patient care and not for the purpose of this study. The liver abscess pus was obtained under ultrasound guidance from 112 amoebic liver abscess (ALA) patients and stored at $-20^{\circ} \mathrm{C}$ in a sterile container until used.

\section{Urine}

A urine specimen was collected from 53 ALA patients. Ten millilitres of urine were collected in a sterile container using aseptic techniques and stored at $-20^{\circ} \mathrm{C}$ until used.

\section{Saliva}

A saliva specimen was collected from 28 ALA patients. Five millilitres of saliva were collected in a sterile container using aseptic techniques and stored at $4{ }^{\circ} \mathrm{C}$ until used.

\section{Entamoeba I6S-like rRNA gene amplification by nested multiplex polymerase chain reaction (NM-PCR)}

\section{Extraction of Entamoeba genomic DNA}

The extraction of Entamoeba genomic DNA from stool, liver abscess pus, urine, and saliva specimens was performed as per the method described previously [21-23].

\section{Primers used}

Based on the sequences of the 16S-like rRNA gene of $E$. histolytica, E. dispar and E. moshkovskii, nested sets of primers (designated E-1/E-2, EH-1/EH-2, ED-1/ED-2 and Mos$1 /$ Mos-2) were used as described previously [21].

\section{Standard strains}

E. histolytica HM-1:IMSS, E. dispar SAW760, and E. moshkovskii Laredo were the standard strains used as positive controls in the present study. The lyophilized DNA of these strains was generously gifted by Dr. C. Graham Clark from the London School of Hygiene and Tropical Medicine, London, UK.

\section{NM-PCR \\ Stool PCR}

The PCR mix composition was as described previously [21].

\section{Liver abscess pus $P C R$}

For genus specific and species specific PCR, the reaction volume of $25 \mu \mathrm{l}$ was comprised of $2.5 \mu \mathrm{l}$ of $10 \times$ PCR buffer (Biogene), $2.0 \mu \mathrm{l}$ of $25 \mathrm{mM} \mathrm{MgCl}_{2}$ (Bangalore genei), $0.75 \mu \mathrm{l}$ of deoxyribo-nucleotide triphosphate mix (10 mM each dNTP, Biogene), $0.3 \mu \mathrm{l}$ ( $5 \mathrm{IU} / \mu \mathrm{l})$ of Taq polymerase (Biogene), $0.25 \mu \mathrm{M}$ primers (IDT) and $2.0 \mu \mathrm{l}$ of template DNA. Amplification was performed in an Eppendorf Thermal cycler [Master cycler gradient].

\section{Urine $P C R$}

The PCR mix composition was the same as described above for liver abscess pus PCR, except that $1.0 \mu \mathrm{l}$ of 25 $\mathrm{mM} \mathrm{MgCl}_{2}$ and $2.5 \mu$ lof template DNA was added. 


\section{Saliva PCR}

The PCR mix composition was the same as described above for liver abscess pus PCR, except that $1.0 \mu \mathrm{l}$ of 25 $\mathrm{mM} \mathrm{MgCl}{ }_{2}$ was added.

The PCR cycle conditions were as described previously [21].

\section{Mutation detection by riboprinting Restriction enzymes}

Restriction enzymes were used to generate comparative riboprints. The restriction enzymes were selected for the $439 \mathrm{bp}, 553 \mathrm{bp}$ and $174 \mathrm{bp}$ PCR product of 16S-like rRNA gene of E. histolytica, E. moshkovskii and E. dispar, respectively, using the online software "NEB cutter V2.0" http:// tools.neb.com/NEBcutter2/index.php. The restriction enzymes used are shown in Table 1.

\section{Restriction enzyme digestion}

In a $25 \mu$ l reaction mix, $15 \mu$ l of nested PCR product was digested with 2.5 units of each restriction enzyme in separate $0.2 \mathrm{ml}$ tubes. The incubation period was for $16 \mathrm{hrs}$ at $37^{\circ} \mathrm{C}$ except for the restriction enzymes Taq I and Mse I where the incubation temperature was $65^{\circ} \mathrm{C}$.

\section{Agarose gel electrophoresis}

Twenty microlitres of the restriction enzyme digested PCR product was separated by electrophoresis through a $2.5 \%$ agarose gel (Agarose Low EEO, Bangalore genie products, Bangalore, India) containing ethidium bromide in $0.5 \times$ Tris-acetate-EDTA (TAE) buffer at $120 \mathrm{~V}$ for $45 \mathrm{~min}$ and was visualized under UV light.

\section{Mutation detection by SSCP}

Preparation of the SSCP gel

In the present study $6 \%$ and $9 \%$ SSCP gels were used. Six percent SSCP gels were used for mutation detection in the 439 bp and 553 bp PCR products of E. histolytica and E. moshkovskii, respectively. A nine percent SSCP gel was used for mutation detection in the 174 bp PCR product of $E$. dispar.

Table I: Restriction enzymes used for riboprinting analysis of partial regions of the I6S-like rRNA genes of E. histolytica, $E$. dispar and $E$. moshkovskii

\begin{tabular}{ccc}
\hline E. histolytica (439 bp) & E. moshkovskii (553 bp) & E. dispar (I74 bp) \\
\hline Xba I & Taq I & Taq I \\
Dde I & Dde I & Dde I \\
Hpyl 88 III & Hpy I88 III & Mse I \\
Mfe I & Mfe I & Sau96 I \\
NIalV & NIalV & \\
Hinf I & Hinf I & \\
Mse I & Mse I & \\
& Sau96 I & \\
\end{tabular}

Preparation of samples for SSCP electrophoresis

Two microlitres of the nested PCR product was diluted into $20 \mu \mathrm{l}$ formamide dye mix in a $0.2 \mathrm{ml}$ microfuge tube. A similar aliquot was diluted into $20 \mu \mathrm{l}$ of gel loading dye. The formamide containing sample was boiled for 6 minutes in a water bath, and then the tube was plunged directly into ice for 10 minutes.

\section{Separation of DNA fragments by SSCP gel electrophoresis}

The wells of the polyacrylamide gel were washed with $1 \times$ TAE electrophoresis buffer. $4 \mu \mathrm{l}$ of denatured DNA (DNA boiled with formamide dye mix) was loaded into the well of polyacrylamide gel. Two microlitres of non-denatured DNA (DNA with gel loading dye) was loaded into another well. Approximately 6-7 V/cm ( 110 V [and $16 \mathrm{~mA}$ ] for $18 \times 14-\mathrm{cm}$ gel) was applied to the gel for $16 \mathrm{hrs}$ at a temperature of $20-25^{\circ} \mathrm{C}$ in an air conditioned room. On completion of the electrophoresis, the gel was silver stained.

\section{Silver staining of SSCP gel}

Silver staining for nucleic acid was performed as per the method described previously [20]. The gel was documented using a densitometer (Biorad) and the results analyzed using "Quantity One" software (Biorad). For long term storage the gel was kept in $10 \%$ glycerol.

\section{Nucleotide sequencing}

PCR products of 16S-like rRNA genes of E. histolytica, E. dispar and E. moshkovskii showing mutation by riboprinting or SSCP analysis, were sequenced on a ABI3730XL sequencer (Macrogen, Seoul, South Korea) using species specific primers. The nucleotide sequences were edited with reference to chromatographs using Chromas (Version 1.62) software and aligned using BioEdit (version 7).

\section{Nucleotide sequence accession numbers}

The nucleotide sequences showing mutations in this study have been deposited into the NCBI GenBank database under accession numbers EF682200-EF682208] (Table 2).

\section{Results Entamoeba I6S-like $r$ RNA gene amplification by NM- PCR \\ Stool PCR}

Seventy stool specimens were positive for the 439 bp PCR product of E. histolytica, 171 stool specimens were positive for the 174 bp PCR product of E. dispar, and 37 stool specimens were positive for the 553 bp PCR product of $E$. moshkovskii.

Liver abscess pus PCR

Ninety liver abscess pus specimens were positive for the 439 bp PCR product of E. histolytica. 
Table 2: E. histolytica and E. moshkovskii isolates obtained from clinical specimens of patients attending JIPMER hospital, Puducherry, showing mutation by PCR-SSCP analysis

\begin{tabular}{cccc}
\hline S. No & Entamoeba species & Clinical specimen & GenBank submission [GenBank accession number] \\
\hline 1 & E. histolytica & Stool & Entamoeba histolytica isolate I [GenBank: EF682200] \\
2 & E. histolytica & Stool & Entamoeba histolytica isolate 2 [GenBank: EF682201] \\
3 & E. histolytica & Stool & Entamoeba histolytica isolate 3 [GenBank: EF682202] \\
4 & E. histolytica & Stool & Entamoeba histolytica isolate 4 [GenBank: EF682203] \\
5 & E. histolytica & Stool & Entamoeba histolytica isolate 5 [GenBank: EF682204] \\
6 & E. moshkovskii & Stool & Entamoeba moshkovskii isolate $6[$ GenBank: EF682206] \\
7 & E. moshkovskii & Stool & Entamoeba moshkovskii isolate 7 [GenBank: EF682207] \\
8 & E. moshkovskii & Stool & Entamoeba moshkovskii isolate 8 [GenBank: EF682208] \\
9 & E. histolytica & Saliva & Entamoeba histolytica isolate I [GenBank: EF682205] \\
\hline
\end{tabular}

\section{Urine $P C R$}

Twenty one urine specimens were positive for the $439 \mathrm{bp}$ PCR product of E. histolytica.

\section{Saliva PCR}

Eight saliva specimens were positive for the 439 bp PCR product of E. histolytica.

\section{Mutation detection by riboprinting}

No intra-species variation in restriction fragment length polymorphism (RFLP) patterns for any restriction enzyme was observed, except for the N1aIV RFLP pattern of the E. histolytica specific 439 bp PCR product from one stool specimen (Stool- 5).

Normal RFLP digestion pattern for the 174 bp, 439 bp, and 553 bp PCR product of E. dispar, E. histolytica and E. moshkovskii respectively with various restriction enzymes are shown in figure 1.

\section{Mutation detection by SSCP}

Five out of 70 E. histolytica specific 439 bp PCR products from stool specimens, one out of 8 E. histolytica specific 439 bp PCR products from saliva specimens, and three out of 37 E. moshkovskii specific 553 bp PCR products from stool specimens showed an altered SSCP profile (i.e. a mobility shift in the acrylamide gel) suggestive of a mutation (Figure 2 and Figure 3).

None of the 171 E. dispar specific 174 bp PCR products from stool specimens, 90 E. histolytica specific 439 bp PCR products from liver abscess pus specimens, or $21 \mathrm{E}$. histolytica specific 439 bp PCR products from urine specimens showed an altered SSCP profile suggestive of a mutation.

The E. histolytica and E. moshkovskii isolates showing mutations by PCR-SSCP analysis are summarized in table 2 .

\section{Nucleotide sequencing}

All four E. histolytica specific 439 bp PCR products from stool specimens (Stool- 1, 2, 3, and 4) showing a muta- tion by SSCP analysis and the E. histolytica specific 439 bp PCR product from stool specimen showing mutation by both SSCP and riboprinting analysis (Stool- 5), were confirmed by nucleotide sequencing. The multiple sequence alignment of these sequencing results and the standard strain E. histolytica HM-1:IMSS is depicted in figure 4 . The comparative electropherogram showing the mutant (Stool- 1, 2, 3, 4, and 5) and normal control (E. histolytica HM-1:IMSS) 16S-like rRNA genes is shown in figure 5.

All three E. moshkovskii PCR products showing mutation by SSCP analysis (Stool- 6, 7, and 8) were confirmed by nucleotide sequencing. The multiple sequence alignment of these sequences and the standard strain E. moshkovskii Laredo is depicted in figure 6 . The comparative electropherogram showing the mutant (Stool- 6, 7, and 8) and normal control (E. moshkovskii Laredo) 16S-like rRNA genes is shown in figure 7 .

The one E. histolytica PCR product from a saliva specimen showing mutation by SSCP analysis was also confirmed by sequencing. The multiple sequence alignment of the results from this saliva specimen and the standard strain E. histolytica HM-1:IMSS is depicted in figure 4. The comparative electropherogram showing the mutant (Saliva-1)

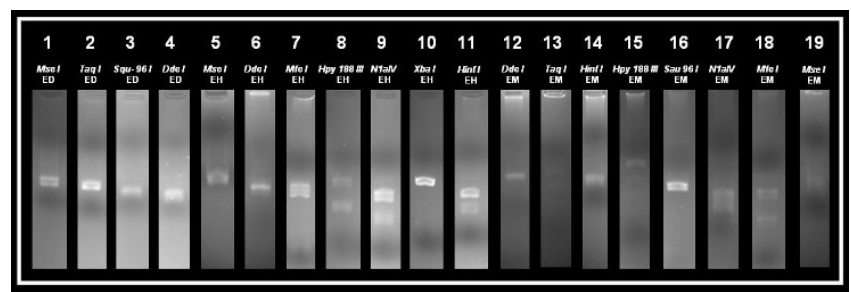

Figure I

Normal RFLP digestion pattern for 174 bp, 439 bp, and 553 bp PCR products of E. dispar, E. histolytica and $E$. moshkovskii respectively with various restriction enzymes. Lane-I to 4 normal riboprints for $E$. dispar (ED); Lane-5 to I I normal riboprints for E. histolytica (EH); Lane- 12 to 19 normal riboprints for E. moshkovskii (EM). 


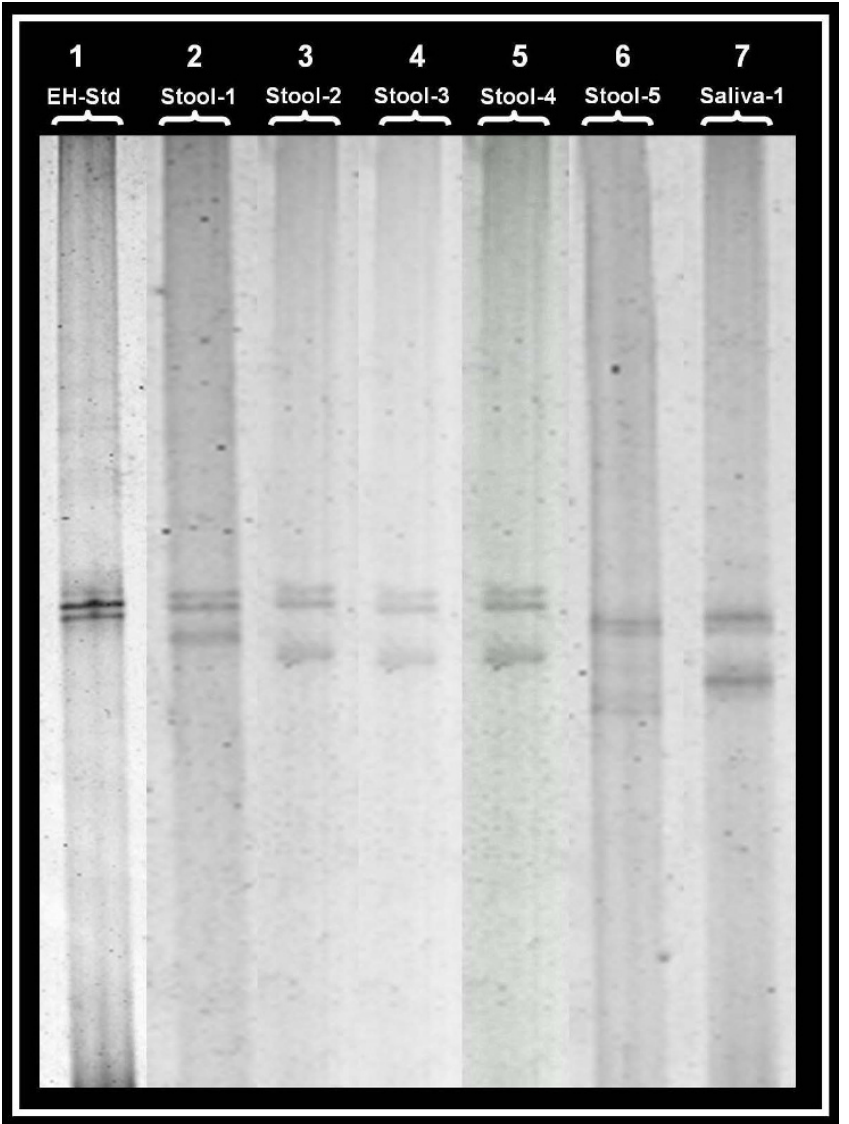

Figure 2

SSCP analysis showing altered profile (mobility shift) for the $\mathbf{4 3 9}$ bp PCR product of $E$. histolytica. Lane-I is for E. histolytica standard DNA (EH-Std); Lane-2, 3, 4, 5, and 6 are for $E$. histolytica DNA from stool specimens showing an altered profile; Lane-7 is for E. histolytica DNA from a saliva specimen showing an altered profile.

and normal control (E. histolytica HM-1:IMSS) is shown in figure 8 .

\section{Discussion}

Mutations and other polymorphisms in genes, gene systems, or whole genomes may play an important role in Entamobea. DNA sequencing is considered the gold standard for identifying such mutations. Nevertheless, DNA sequencing method is cumbersome and costly when large numbers of samples need to be rapidly analyzed. The method, therefore, is not always suitable for use in epidemiological studies.

In the present study, PCR products of 16S-like rRNA gene of E. histolytica, E. moshkovskii and E. dispar were subjected to screening for mutation by riboprinting and SSCP analysis. These products were of a relatively small sizes, $553 \mathrm{bp}$ for E. moshkovskii, 439 bp for E. histolytica and 174 bp for

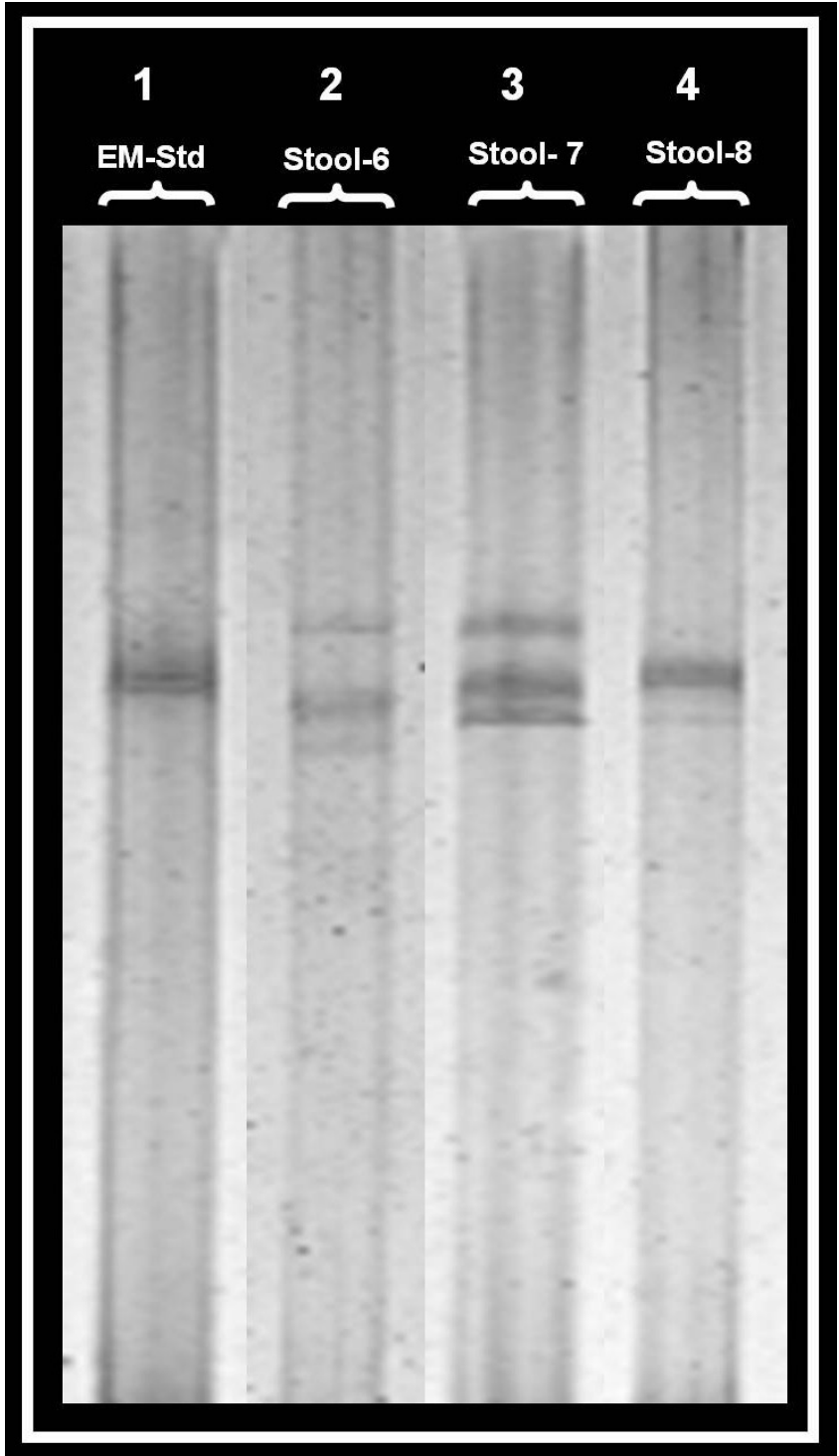

Figure 3

SSCP analysis showing altered profile (mobility shift) for the $\mathbf{5 5 3}$ bp PCR product of E. moshkovskii. Lane-I is for E. moshkovskii standard DNA (EM-Std); Lane-2, 3 , and 4 are for $E$. moshkovskii DNA from stool specimens showing an altered profile.

E. dispar, and were found to be particularly suitable for SSCP analysis.

Riboprinting analysis detected a mutation in only one of the E. histolytica samples, from a stool specimen (Stool5 ); the alteration in the RFLP pattern (i.e. the PCR product remained undigested) was due to substitution of $\mathrm{G}$ by $\mathrm{A}$ in the recognition site of $\mathrm{N} 1 \mathrm{aIV}$. The inability of riboprinting to detect mutations in a majority of Entamoeba isolates is due to the limitation that RFLP detects mutation only when they occur in restriction endonuclease cut sites. 


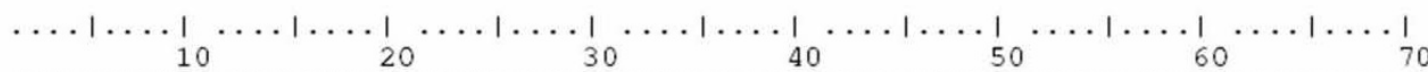

$\begin{array}{llll}10 & 20 & 30 & 40\end{array}$

50

60

EH Std

Stool 1 Stool 2 Stool 3 Stool 4 Stool 5

Saliva 1

EH Std

Stool 1 Stool 2

Stool 3

Stool 4

Stool 5

Saliva 1

EH Std

Stool 1

Stool 2

Stool 3

Stool 4

Stool 5

Saliva 1

EH Std

Stool 1

Stool 2

Stool 3

Stool 4

Stool 5

Saliva 1

EH Std Stool 1 Stool 2 Stool 3 Stool 4 Stool 5 Saliva 1

EH Std Stool 1 Stool 2 Stool 3 Stool 4 Stool 5 Saliva 1 TCTTGAGTTT ATGGACTTCA GGGGGAGTAT GGTCACAAGg CTGAAACTTA AAgGAATtGA CGGAAgGGCA TCTTGAGTTT ATGGACTTCA GGGGGAGTAT GGTCACAAGg CTGAAACTTA AAgGAATTGA CGGAAGGgCA TCTTGAGTTT ATGGACTTCA GGGGGAGTAT GGTCACAAGg CTGAAACTTA AAgGAATTGA CGGAAGGGCA TCTTGAGTTT ATGGACTTCA GGGGGAGTAT GGTCACAAGg CTGAAACTTA AAgGAATTGA CGGAAGgGCA TCTTGAGTTT ATGGACTTCA GGGGGAGTAT GGTCACAAGG CTGAAACTTA AAGGAATTGA CGGAAGGGCA TCTTGAGTTT ATGGACTTCA GGGGGAGTAT GGTCACAAGG CTGAAACTTA AAGGAATTGA CGGAAgGGCA TCTTGAGTTT ATGGACTTCA GGGGGAgTAT GGTCACAAGg CTGAAACTTA AAgGAATtGA CGgAagGgCA

$\ldots|\ldots|$ | $\ldots|\ldots| \ldots|\ldots| \ldots \mid$ | $\ldots|\ldots| \ldots|\ldots| \ldots|\ldots| \ldots|\ldots| \ldots|\ldots| \ldots \mid$ 80 100 110 120 130 140 CACCAGGAGT GGAGCCTGCG GCTTAATTTG ACTCAACACG GGAAAACTTA CCAAGACCGA ACAGTAGAAG CACCAGGAGT GGAGCCTGCG GCTTAATTTG ACTCAACACG GGAAGACTTA CCAAGACCGA ACAGTTGAAG CACCAGGAGT GGAGCCTGCG GCTTAATTTG ACTCAACACG GGAAAACTTA CCAAGACCGA ACAGTAGAAG CACCAGGAGT GGAGCCTGCG GCTTAATTTG ACTCAACACG GGAAAACTTA CCAAGACCGA ACAGTAGAAG CACCAGGAGT GGAGCCTGCG GCTTAATTTG ACTCAACACG GGAAAACTTA CCAAGACCGA ACAGTAGA.AG CACCAGGAGT GAAGCCTGCG GCTTAATTTG ACTCAACACG GGAAAACTTA CCAAGACCGA ACAGTAGAAG CACCAGGAGT GGAGCCTGCG GATTAATTTG ACTCAACACG GGAAAACTTA CCAAGACCGA ACAGTAGAAG

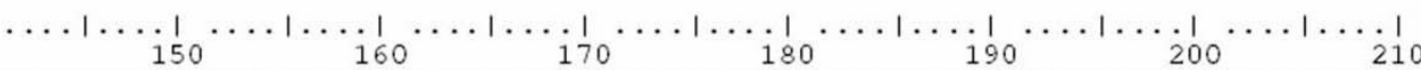
GAATGACAGA TTAAGAGTTC TTTCATGATT TATTGGGTAg TGGTGCATGg CCGTTCTTAG TTGGTGGAGT GAATGACAGA TTAAGAGTTC TTTCATGATT TATTGGGTAG TGGTGCATGg CCGTTCTTAG TTGGTGGAGT GAATGACAGA TTAAGAGTTC TTTCATGATT TATTGGGTAG TGGTGCATGG CCGTTCTTAG TTGGTGGAGT GAATGACAGA TTAAGAGTTC TTTCATGATT TATTGGGTAG TGGTGCATGG CCGTTCTTAG TTGGTGGAGT GAATGACAGA TTAAGAGTTC TTTCATGATT TATTGGGTAG TGGTGCATGG CCGTTCTTAG TTGGTGGAGT GAATGACAGA TTAAGAGTTC TTTCATGATT TATTGGGTAG TGGTGCATGG CCGTTCTTAG TTGGTGGAGT

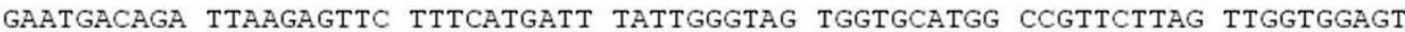

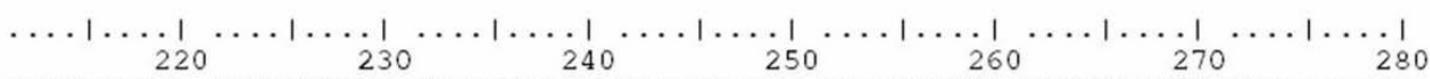
GATTTGTCAG GTTAATTCCG GTAACGAACG AGACTGAAAC CTATTAATTA GTTTTCTGCC TATAAGACAG GATTTGTCAG GTTAATTCCG GTAACGAACG AGACTGAAAC CTATTAATTA GTTTTCTGCC TATAAGACAG GATTTGTCAG GTTAATTCCG GTAACGAACG AGACTGAAAC CTATTAATTA GTTTTCTGCC TATAAGACAG GATTTGTCAG GTTAATTCCG GTAACGAACG AGACTGAAAC CTATTAATTA GTTTTCTGCC TATAAGACAG GATTTGTCAG GTTAATTCCG GTAACGAACG AGACTGAAAC CTATTAATTA GTTTTCTGCC TATAAGACAG GATTTGTCAG GTTAATTCCG GTAACGAACG AGACTGAAAC CTATTAATTA GTTTTCTGCC TATAAGACAG GATTTGTCAG GTTAATTCCG GTAACGAACG AGACTGAAAC CTATTAATTA GTTTTCTGCC TATAAGACAG

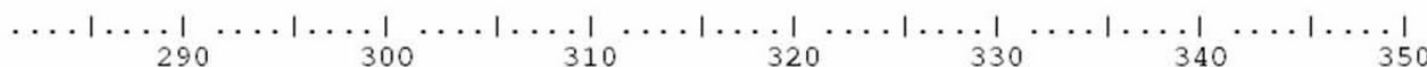
AAATGTTCGC AAGAACAGGT GCGTAAGTAC CACTTCTTAA AGGGACACAT TTCAATTGTC CTATTTTAAT AAATGTTCGC AAGAACAGGT GCGTAAGTAC CACTTCTTAA AGGGACACAT TTCAATTGTC CTATTTTAAT AAATGTTCGC AAGAACAGGT GCGTAAGTAC CACTTCTTAA AGGGACACAT TTCAATTGTC CTATTTTAAT AAATGTTCGC AAGAACAGGT GCGTAAGTAC CACTTCTTAA AGGGACACAT TTCAATTGTC CTATTTTAAT AAATGTTCGC AAGAACAGGT GCGTAAGTAC CACTTCTTAA AGGGACACAT TTCAATTGTC CTATTTTAAT AAATGTTCGC AAGAACAGGT GCGTAAGTAC CACTTCTTAA AGGGACACAT TTCAATTGTC CTATTTTAAT AAATGTTCGC AAGAACAGGT GCGTAAGTAC CACTTCTTAA AGGGACACAT TTCAATTGTC CTATTTTAAT

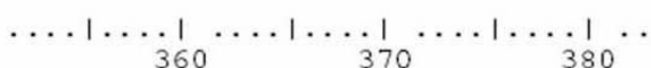

TGT-AGTTAT CTAATTCGGT TAGGACCTCT TA

TGT-AGTTAT CTAATTCGGT TAGGACCTCT TA

TGTTAGTTAT CTAATTCGGT TAGGACCTCT TA

TGTTAGTTAT CTAATTCGGT TAGGACCTCT TA

TGTTAGTTAT CTAATTCGGT TAGGACCTCT TA

TGTTAGTTAT CTAATTCGGT TAGGACCTCT TA

TGT-AGTTAT CTAATTCGGT TAGGACCTCT TA

\section{Figure 4}

Multiple sequence alignment of $E$. histolytica specific 439 bp PCR products from clinical specimens (Stool- I to 5 and Saliva-I) and the standard strain E. histolytica HM-I:IMSS (EH-Std). The sequence variations are highlighted in red. 


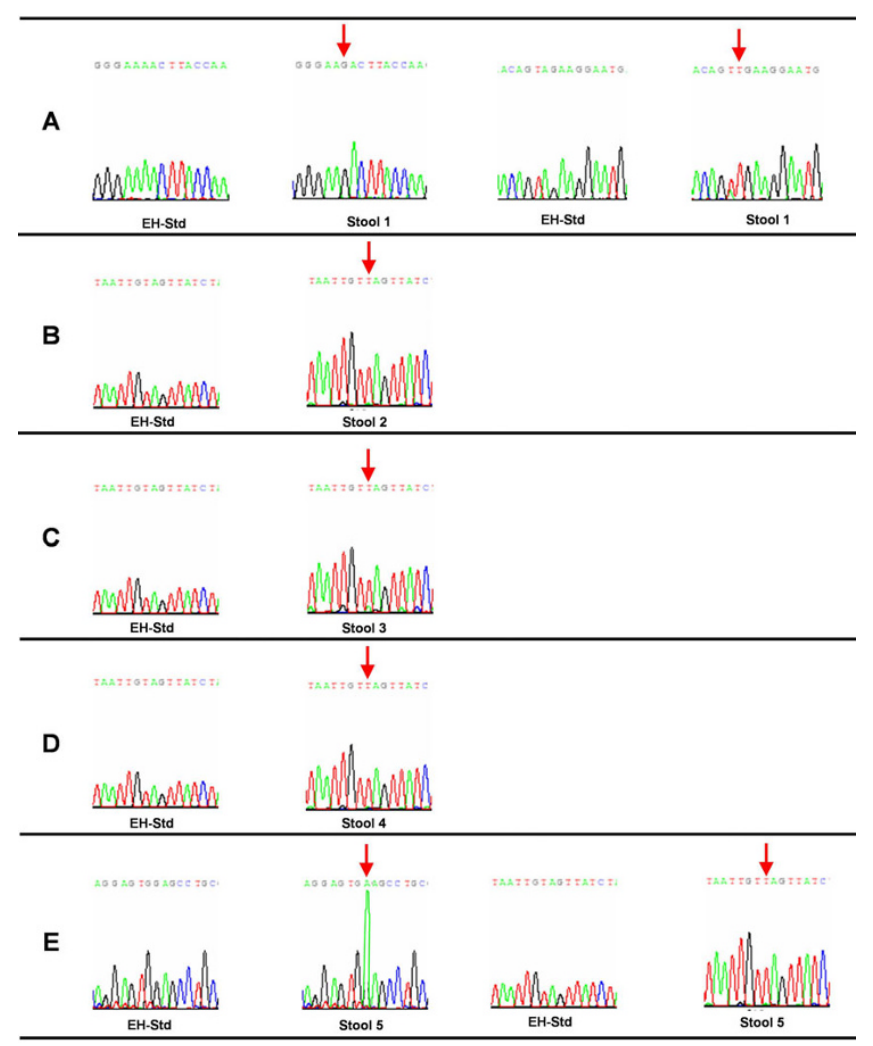

Figure 5

Electropherogram showing the mutant (Stool-I to 5) and normal control E. histolytica HM-I IMSS (EH-

Std) I6S-like rRNA genes. Chromatogram showing the sequence variation is indicated by an arrow. The sequencing revealed substitution of $A$ by $G$ and substitution of $A$ by $T$ $(A)$, insertion of $T(B)$, insertion of $T(C)$, insertion of $T(D)$, and substitution of $G$ by $A$ and insertion of $T(E)$.

However, SSCP analysis detected mutation in a total of five E. histolytica and three E. moshkovskii isolates from stool and one E. histolytica isolate from saliva. This may be attributed to the ability of SSCP, unlike RFLP, to detect any mutation in a DNA sequence. The SSCP analysis results that were suggestive of mutations were reproducible (i.e. SSCP analysis showed identical profiles in three separate experiments).

In this study none of the $171 \mathrm{E}$. dispar isolates showed characteristics suggestive of mutation by SSCP analysis, perhaps due to the screening of only a $174 \mathrm{bp}$ region of the gene. The chances of finding a mutation in such a small region is less than in larger regions studied for the other two species.

Although it was observed that riboprinting was useful for screening a large number of samples, especially when looking for a specific single nucleotide polymorphism, the method has some inherent disadvantages. In this method, a large amount of amplicon $(15 \mu \mathrm{l})$ is needed for digestion with each of several enzymes, and each clinical sample ends up being electrophoresed on several gels, making it a very laborious and time consuming procedure.

SSCP analysis, on the other hand, was found to be simple and convenient in the present study. The results were obtained from only $2 \mu \mathrm{l}$ of PCR product on a single SSCP gel, which in the long run turned out to be much more economical. The total time needed for PCR-SSCP was less than 24 hours. The SSCP technique developed and evaluated in our laboratory provides us with a rapid tool for detecting mutations in Entamoeba. This method could conveniently supplement other methods of mutation detection analysis on large-scale. The limitation of SSCP, although minor, is that it detects the occurrence of single base mutations in a segment of DNA but does not give any information on the type or location of the base changes, which have to be confirmed by nucleotide sequencing.

In the present study, the results showed that SSCP analysis was able to detect even single nucleotide differences (Figure 5, Figure 7, and Figure 8). Nucleotide sequences were verified three times by sequencing of products of different PCR reaction from the same source of DNA to rule out any discrepancy due to sequencing errors. The sequencing analysis identified four new E. histolytica genotypes and three new E. moshkovskii genotypes (Figure 4 and Figure 6). Recently, a report from Bangladesh [16] studied clinical specimens using six tRNA-linked STR loci, and detected 85 genotypes in 111 unrelated samples. Another report from Bangladesh [15] also studied clinical samples but used a nested PCR-RFLP of the SREHP gene. Twenty five genotypes among 42 intestinal isolates and 9 genotypes among 12 ALA samples were found. Out of 9 genotypes from liver abscess samples, 8 were unique to the ALA samples investigated. In our study no unique genotypes among any of the liver abscess samples and urine samples from ALA cases were found, but out of 5 E. histolytica genotypes from stool samples 4 were unique to the stool samples investigated. In addition, our study also detected one unique E. histolytica genotype from a saliva sample from an ALA case and three new E. moshkovskii genotypes from stool samples. Clark and Diamond [6] combined results of both PCR-RFLP of SREHP and amplification of the SSG locus to report 16 different genotypes among 18 isolates of E. histolytica from varied geographical locations. Haghighi et al. [11] reported a total of 53 different genotypes among 63 isolates of E. histolytica, mostly from Japan and Thailand, using sequencing of four loci (two tRNA-linked STR loci, chitinase, and SREHP). The high level of diversity reported from different geographic locations suggest that the rapid generation of new Entamoeba 
EM Std

Stool-6 Stool-7 Stool-8

EM Std Stool-6 Stool-7 Stool-8

EM Std Stool-6 Stool-7 Stool-8

EM Std Stool-6 Stool-7 Stool-8

\section{EM Std} Stool-6 Stool-7 Stool-8

\section{EM Std} Stool-6 Stool-7 Stool-8

\section{EM Std} Stool-6 Stool-7 Stool-8

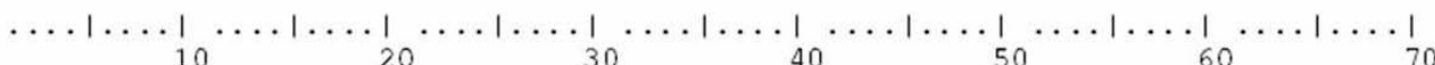

AGTATGGTCA CAAGgCTGAA ACTTAAAGGA ATTGACGGAA GGGCACACCA GGAGTGGAGC CTGCGGCTTA AGTATGGTCA CAAGGCTGAA ACTTAAAgGA ATTGACGGAA GGGCACACCA GGAGTGGAGC CTGCGGCTTA AgtATGGTCA CAAGGCTGA. ACTTAAAGGA ATtGACGGAA GGGCACACCA GGAGTGGAGC CTGCGGCTTA AGTATGGTCA CAAGGCTGAA ACTTAAAGGA ATTGACGGAA GGGCACACCA GGAGTGGAGC CTGCGGCTTA

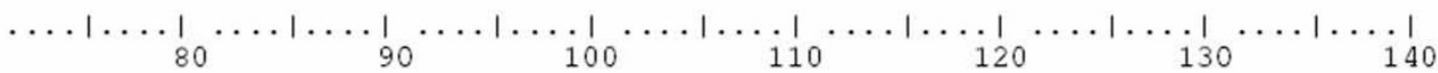

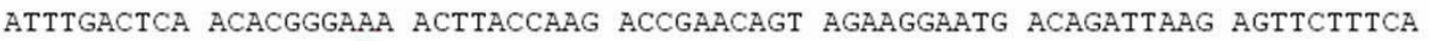
ATTTGACTCA ACACGGGAGA ACTTACCAAG ACCGAACAGT AGAAGGAATG ACAGATTAAG AGTTCTTTCA

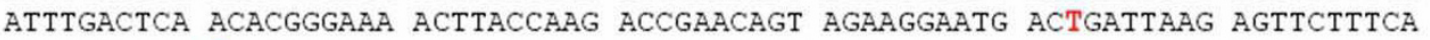

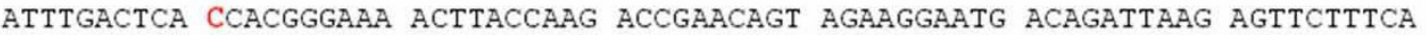

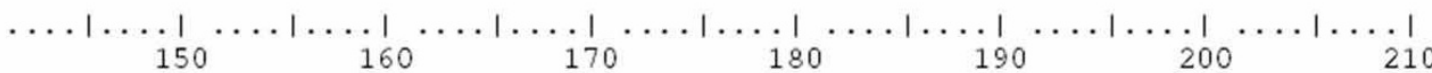
TGATTTATTG GGTAGTGGTG CATGGCCGTT CTTAGTTGgT GGAGTGATTT GTCAGgtTAA TTCCGgtAAC TGATTTATTG GGTAGTGGTG CATGGCCGTT CTTAGTTGGT GGAGTGATTT GTCAGGTTAA TTCCGGTAAC TGATTTATTG GGTAGTGGTG CATGGCCGTT CTTAGTTGGT GGAGTGATTT GTCTGGTTAA TTCCGGTAAC TGATTTATTG GGTAGTGGTG CATGGCCGTT CTTAGTTGGT GGAGTGATTT GTCAGGTTAA TTCCGGTAAC

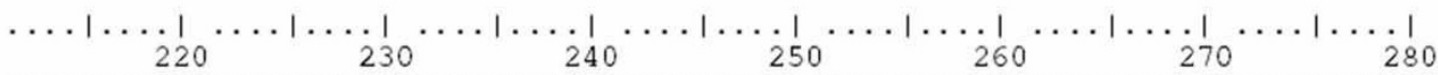
GAACGAGACT GAAACCTATT AATTAGTTTC CTGCCTATAC GACAGGAATC TCCGCAAGGT CAGGTGCCTC GAACGAGACT GAAACCTATT AATTAGTTTC CTGCCTATAC GACAGGAATC TCCGCAAGGT CAGGTGCCTC GAACGAGACT GAAACCTATT AATTAGTTTC CTGCCTATAC GACAGGAATC TCCGCAAGGT CAGGTGCCTC GAACGAGACT GAAACCTATT AATTAGTTTC CTGCCTATAC GACAGGAATC TCCGCAAGGT CAGGTGCCTC

$$
\ldots|\ldots| \ldots|\ldots| \ldots|\ldots| \ldots|\ldots| \ldots|\ldots| \ldots|\ldots| \ldots|\ldots| \ldots|\ldots| \ldots|\ldots| \ldots \mid
$$

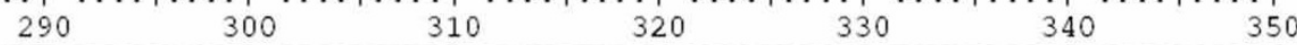

GGTACCACTT CTTAAAGGGA CACATTTCAA TTGTCTCATT TTAATCGATG TCTCTGGCTC CGGTCAGAAC GGTACCACTT CTTAAAGGGA CACATTTCAA TTGTCTCATT TTAATCGATG TCTCTGGCTC CGGTCAGAAC GGTACCACTT CTTAAAGGGA CACATTTCAA TTGTCTCATT TTAATCGATG TCTCTGGCTC CGGTCAGAAC GGTACCACTT CTTAAAGGGA CACATTTCAA TTGTCTCATT TTAATCGATG TCTCTGGCTC CGGTCAGAAC

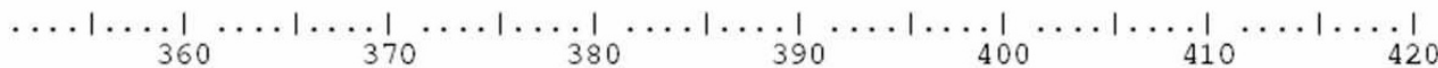
TCTTTTAACG TGAGAAAAa AAAAAgGAag CATTCAGCAA TAACAGGTCT GTGATGCCCT TAGACATCTT TCTTTTAACG TGAGAAAAAG AAAAAGGAAG CATTCAGCAA TAACAGGTCT GTGATGCCCT TAGACATCTT TCTTTTAACG TGAGAAAAAG AAAAAGGAAG CATTCAGCAA TAACAGGTCT GTGATGCCCT TAGACATCTT TCTTTTAACG TGAGAAAAA AAAAAGGAag CATTCAGCAA TAACAGGTCT GTGATGCCCT TAGACATCTT

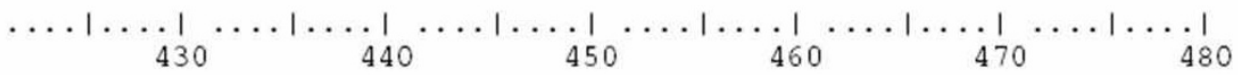

GGGCCGCACG CGCGCTACAA TGGAGTTACT AGAGAGTATT tTATCATCCA AGCCTTATAT GGGCCGCACG CGCGCTACAA TGGAGTTACT AGAGAGTATT TTATCATCCA AGCCTTATAT GGGCCGCACG CGCGCTACAA TGGAGTTACT AGAGAGTATT TTATCATCCA AGCCTTATAT GGGCCGCACG CGCGCTACAA TGGAGTTACT AGAGAgTATT TTATCATCCA AGCCTTATAT

\section{Figure 6}

Multiple sequence alignment of the E. moshkovskii specific 553 bp PCR products from stool specimens (Stool-6 to 8) and the standard strain E. moshkovskii Laredo (EM-Std). The sequence variations are highlighted in red. 


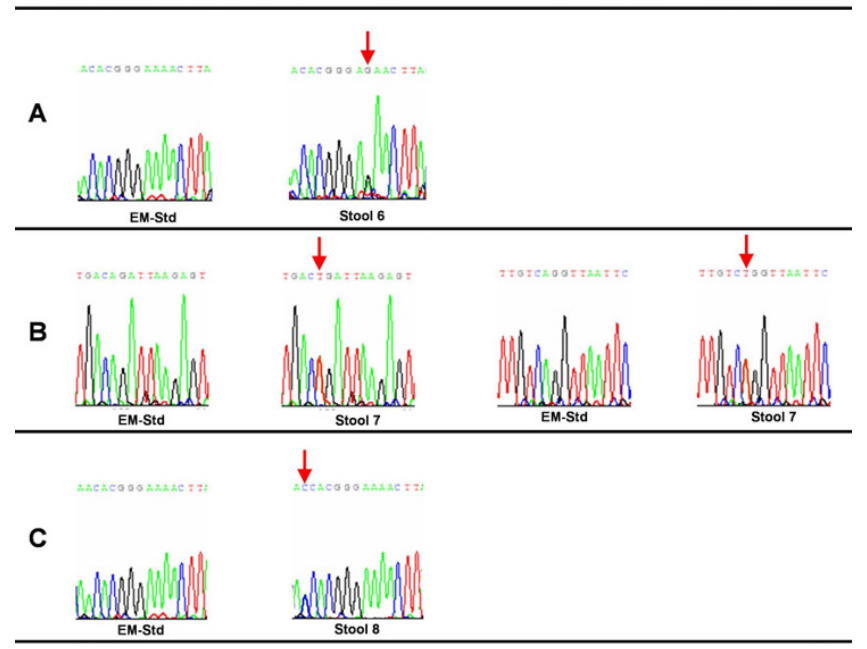

Figure 7

Electropherogram showing the mutant (Stool-6 to 8) and normal control E. moshkovskii Laredo (EM-Std)

I 6S-like rRNA genes. Chromatogram showing the sequence variation is indicated by an arrow. The sequencing revealed substitution of $A$ by $G(A)$, substitution of $A$ by $T$ and substitution of $A$ by $T(B)$, and substitution of $A$ by $C(C)$

variants is taking place. The occurrence of new E. histolytica and E. moshkovskii genotypes in the area of Puducherry, India, may be a unique finding and the close relationship of these genotypes with a recognized human pathogen like E. histolytica should prompt further studies.

In this study, the presence of mutations was explored in a region of 16S-like rRNA gene of E. histolytica, E. dispar and E. moshkovskii by applying riboprinting and SSCP analysis. Further studies are needed to extend mutation detection to the complete ribosomal RNA gene of these species, which will possibly reveal much more about genetic variation in Entamoeba.

\section{Conclusion}

The present study has revealed the subsistence of mutation in ribosomal RNA gene of E. histolytica and E. moshk-

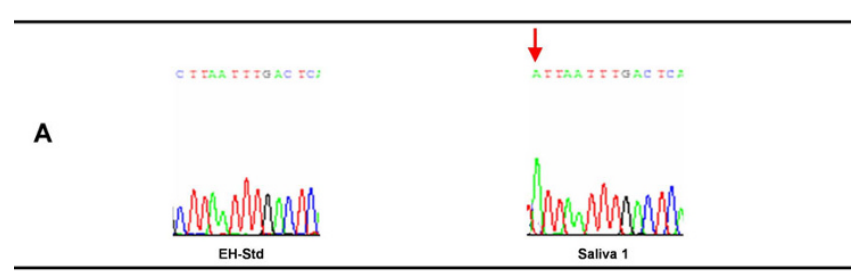

\section{Figure 8}

Electropherogram showing the mutant (Saliva-I) and normal control E. histolytica HM-I:IMSS (EHStd) I6S-like rRNA genes. Chromatogram showing the sequence variation is indicated by an arrow. The sequencing revealed substitution of $C$ by $A(A)$ ovskii, which points towards the existence of intra-species genetic variation in E. histolytica and E. moshkovskii isolates infecting humans.

\section{Competing interests}

The authors declare that they have no competing interests.

\section{Authors' contributions}

SCP supervised and coordinated the study, and helped to draft the manuscript. KK carried out the experimental work, and drafted the manuscript.

\section{Acknowledgements}

We are grateful to Dr. C. Graham Clark from London School of Hygiene and Tropical Medicine for providing us with lyophilized DNA of standard cultures of E. histolytica HM-I:IMSS, E. dispar SAW760, and E. moshkovskii Laredo.

\section{References}

I. World Health Organization: Amoebiasis. Wkly Epidemiol Rec 1997, 72:97-99.

2. Lösch FA: Massive development of amebas in the large intestine. Translation from the original in Russian, 1875. Am J Trop Med Hyg 1975, 24:383-392.

3. Parija SC: Amoebae: Intestinal Amoebae Pathogenic Free-living Amoebae. In Text book of medical parasitology Edited by: Parija SC. Chennai: All India Publishers \& Distributors; 2006:29-64.

4. Clark CG, Diamond LS: Ribosomal RNA genes of 'pathogenic' and 'nonpathogenic' Entamoeba histolytica are distinct. Mol Biochem Parasitol I99I, 49:297-302.

5. Bhattacharya S, Bhattacharya A, Diamond LS: Entamoeba histolytica extrachromosomal circular ribosomal DNA: analysis of clonal variation in a hypervariable region. Exp Parasitol 1992, 74:200-204.

6. Clark CG, Diamond LS: Entamoeba histolytica: a method for isolate identification. Exp Parasitol 1993, 77:450-455.

7. Sehgal D, Bhattacharya A, Bhattacharya S: Analysis of a polymorphic locus present upstream of rDNA transcription units in the extrachromosomal circle of Entamoeba histolytica. Mol Biochem Parasitol 1993, 62:129-130.

8. Ghosh S, Frisardi M, Ramirez-Avila L: Molecular epidemiology of Entamoeba spp.: evidence of a bottleneck (demographic sweep) and transcontinental spread of diploid parasites. J Clin Microbiol 2000, 38:38I5-382I.

9. Zaki M, Clark CG: Isolation and characterization of polymorphic DNA from Entamoeba histolytica. J Clin Microbiol 200I, 39:897-905.

10. Li E, Kunz-Jenkins C, Stanley SL Jr: Isolation and characterization of genomic clones encoding a serine-rich Entamoeba histolytica protein. Mol Biochem Parasitol 1992, 50:355-357.

II. Haghighi A, Kobayashi S, Takeuchi T, Thammapalerd N, Nozaki T: Geographic diversity among genotypes of Entamoeba histolytica field isolates. J Clin Microbiol 2003, 4 I:3748-56.

12. Haghighi A, Kobayashi S, Takeuchi T, Masuda G, Nozaki T: Remarkable genetic polymorphism among Entamoeba histolytica isolates from a limited geographic area. J Clin Microbiol 2002, 40:408I-90.

13. Simonishvili S, Tsanava S, Sanadze K, Chlikadze R, Miskalishvili A, Lomkatsi N, Imnadze P, Petri WA Jr, Trapaidze N: Entamoeba histolytica: the serine-rich gene polymorphism-based genetic variability of clinical isolates from Georgia. Exp Parasitol 2005 , I 1 0:313-7.

14. Rivera WL, Santos SR, Kanbara H: Prevalence and genetic diversity of Entamoeba histolytica in an institution for the mentally retarded in the Philippines. Parasitol Res 2006, 98:106-10.

15. Ayeh-Kumi PF, Ali IM, Lockhart LA, Gilchrist CA, Petri WA Jr, Haque $R$ : Entamoeba histolytica: genetic diversity of clinical isolates from Bangladesh as demonstrated by polymorphisms in the serine-rich gene. Exp Parasitol 200I, 99:80-8. 
16. Ali IK, Mondal U, Roy S, Haque R, Petri WA Jr, Clark CG: Evidence for a link between parasite genotype and outcome of infection with Entamoeba histolytica. J Clin Microbiol 2007, 45:285-9.

I7. Zaki M, Clark CG: Isolation and characterization of polymorphic DNA from Entamoeba histolytica. J Clin Microbiol 200I, 39:897-905.

18. Pinheiro SM, Maciel RF, Morais MA Jr, Aca IS, Carvalho LB Jr, Coimbra $M R$ : Genetic characterization of Entamoeba dispar isolates in Northeast Brazil. Acta Trop 2005, 94:35-40.

19. Ramos F, García G, Valadez A, Morán P, González E, Gómez A, Melendro El, Valenzuela O, Ximénez C: E. dispar strain: analysis of polymorphism as a tool for study of geographic distribution. Mol Biochem Parasitol 2005, I 4 I: I75-7.

20. Sambrook J, Russell DW: Molecular Cloning, A Laboratory Manual New York: Cold Spring Harbor Laboratory Press; 2000.

21. Khairnar K, Parija SC: A novel nested multiplex polymerase chain reaction (PCR) assay for differential detection of Entamoeba histolytica, E. moshkovskii and $E$. dispar DNA in stool samples. BMC Microbiol 2007, 24:47.

22. Parija SC, Khairnar K: Detection of excretory Entamoeba histolytica DNA in the urine, and detection of $E$. histolytica DNA and lectin antigen in the liver abscess pus for the diagnosis of amoebic liver abscess. BMC Microbiol 2007, I 8:4I.

23. Khairnar K, Parija SC: Detection of Entamoeba histolytica DNA in the saliva of amoebic liver abscess patients who received prior metronidazole treatment. J Health Popul Nutr in press.

\section{Pre-publication history}

The pre-publication history for this paper can be accessed here:

http://www.biomedcentral.com/1471-2334/8/131/pre

pub

Publish with Bio Med Central and every scientist can read your work free of charge

"BioMed Central will be the most significant development for disseminating the results of biomedical research in our lifetime. "

Sir Paul Nurse, Cancer Research UK

Your research papers will be:

- available free of charge to the entire biomedical community

- peer reviewed and published immediately upon acceptance

- cited in PubMed and archived on PubMed Central

- yours - you keep the copyright 